\title{
The valuation of emerging media arts in the age of digital reproduction
}

\author{
David R. Burns \\ Southern Illinois University Carbondale \\ Department of Radio-Television \\ 1100 Lincoln Drive, MC: 6609 \\ Carbondale, IL 62901-6609, USA \\ drburns@siu.edu
}

\begin{abstract}
The proliferation of artists, audiences, and participants who have the ability to create mirror copies of original digital media arts work challenges us to re-examine how value is assigned to digital media arts work. Historically, space and capital limitations restricted the public's accessibility to artwork, but the growth of mass digital reproduction and alternative forms of art exhibition spaces is having a profound effect on the experience and valuation of digital media arts work. For example, the online distribution of digital media arts work across networks facilitates the circumvention of traditional valuation models. In this essay, I explore the background and challenges to assigning value to digital media arts work. This essay also investigates alternative models of exhibition and valuation of digital media arts work in the institutional, private, and public spheres.
\end{abstract}

Value. Digital. Media. Arts. Work. Copies. Reproduction. Exhibition. Collectors. Art. Artwork. Lossless. Curator. Collector. Fine. Net. New. Emerging. Valuation. Space. Capital. Distribution. Public. Private. Internet. Institution.

\section{INTRODUCTION}

The proliferation of artists, audiences, and participants who have the ability to create mirror copies of original digital media arts work challenges us to re-examine how value is assigned to this type of work. Historically, space and capital limitations restricted the public's accessibility to artwork, but the growth of mass digital reproduction and alternative forms of art exhibition space is having a profound effect on the valuation of digital media arts work. In this essay, I explore how the economics of dematerialisation, preservation, technology, and accessibility of digital media arts work create challenges for its valuation and exhibition. I also explore possible solutions to these challenges in the valuation and exhibition of digital media arts work.

\section{CHALLENGES TO VALUING DIGITAL MEDIA ARTS WORK}

\subsection{Economics of dematerialisation}

The traditional way that economic value is assigned to fine artwork is based upon the limited availability of the original, material artwork. An original analogue work of fine artwork is valued because a mirror copy is impossible to reproduce from the original. For example, the original Mona Lisa is only found in the Louvre and because there is only one original painting, a high value is assigned to the Louvre's canvas. Visitors place value on accessing the unique physical painting and pay admissions fees to visit the Louvre and experience the original Mona Lisa. Based on this valuation model, original, physical, fine artworks, like paintings on a canvas that are in limited supply, are assigned a high economic value because they are originals and mirror copies cannot be reproduced from the original (Sturken \& Cartwright, 2001). Because there is only one original, people who want to experience the original work of art pay for this experience through admission fees to museums or buying original, one-of-a-kind works of art.

This traditional valuation model based upon limited availability is more difficult to apply to newer forms of reproducible arts and media. In 1936, Walter Benjamin helped set the stage for challenging this traditional valuation model. Benjamin (1968) argued that the practice of placing higher values on one-of-a-kind images was losing currency because of the introduction of new forms of reproducible art using media like photography and film. Digital media arts work present even greater challenges to 
traditional models of valuing artwork than analogue photography and film because digital media arts work can be infinitely copied without loss of quality. According to Sturken \& Cartwright (2001), in 'digital images, the idea of the difference between a copy and an original is nonexistent'. Each copy of an original digital media arts work is lossless and identical to the original work.

The growth in popularity of digital media arts work presents new challenges to assigning value to artwork that can be copied multiple times with each copy indistinguishable from the original. As Sturken \& Cartwright (2001) explain, an 'image being unique makes no sense with digital images'. This lossless reproducibility of digital media arts work challenges the traditional valuation model because digital media arts work cannot be valued based solely on its physical materiality or scarcity. For example, using the traditional valuation model to assign value to digital video art on DVD is challenging because original digital video art DVDs can be copied thousands of times with each digital copy indistinguishable from the original. Likewise, using the traditional valuation model to assign value to generative digital media arts work projects that are generated from computer code is difficult. Lossless, identical copies of original digital media arts installations and computergenerated works can be easily transferred from one computer to another.

Net Art is another example of a type of digital media arts work that presents new challenges to assigning value to artwork. Original Net Art files stored virtually on a server can be inexpensively copied and distributed over digital networks to audiences' home computers. These copies of the Net Art files downloaded to audiences' home computers are exactly the same quality as the artist's original Net Art stored on a collection's server.

The fact that lossless, identical copies can be made from original digital media arts work creates challenges for digital media artists, curators, and collectors. Digital media artists, curators, and collectors struggle with assigning value to both original digital media arts work that can be copied and the lossless, identical copies of original digital media arts work. Some collectors and curators are waiting for an alternative valuation model before adding digital media arts work to their inventory. This type of wait-and-see approach delays the valuation and collection of digital media arts work.

The traditional valuation model based upon limited availability is more difficult to apply to digital media arts work. The " "scarcity equals the value" model does not necessarily work when it comes to digital art' (Paul, 2008). Digital media arts work both present new challenges to the traditional valuation model and face challenges with curators and institutions that subscribe to this traditional valuation model. Valuing digital media arts work and the lossless, identical copies of digital media arts work are important challenges facing contemporary artists, curators, and collectors.

\subsection{Preservation}

The tradition of assigning value to artwork based on its physical materiality presents a challenge to valuing digital media arts work. When determining an artwork's long-term socio-economic value, collectors and curators place great importance on the work's physical materials. The durability of a work's physical materials increases the work's value by allowing it to stand the test of time and granting it accessibility to transmit meaning and value in the future. Innis (1972) describes the importance of durability of physical materials for transmitting meaning and value of work: 'The concepts of time and space reflect the significance of media to civilisation. Media that emphasised time are those that are durable in character, such as parchment, clay, and stone' (Innis, 1972). For example, stone sculptures and clay pots are durable works that have been preserved and are easily accessed in major collections. With regular maintenance, future generations will have access to and be able to value these objects. It is this sense of permanence and durability that adds value to traditional artwork.

This reliance on assigning value to artwork based on its physical materiality presents challenges to the valuation of digital media arts work. Digital media arts work's transition to virtual materials and technology opens up alternatives to creating physical, material artworks and makes valuation based on the durability of physical materials difficult. Digital media arts work are dematerialised and their digital and virtual nature releases them from the constrictions of physical materiality. For example, the dematerialised nature of digital media arts work that are dynamically generated by participants' random interactions with computer code makes preservation of this work difficult. The durability of digital media arts work differs from Innis's (1972) concept of physical durability because digital media arts work rely less on physical materials and more on digital bits and bytes. As the technology used in a digital media arts work becomes obsolete, it becomes more challenging to preserve and replicate the experience of the work. If the technology needed to experience the work is no longer available, valuing the digital media arts work will be difficult. Collectors will be left with dematerialised works that are difficult to value because of the technological challenges to experiencing the work. 
As the technology used to exhibit digital media arts work advances, older technologies used to display older digital media arts work become obsolete. This is a challenge to valuing and exhibiting work when 'artifacts are so closely linked to specific software and hardware that they cannot be used outside these specific environments' (Barber, 2008). For example, software art relying on custom code written and maintained by an artist might not be supported after the artist dies. If there is diminished or no technical support and maintenance available to keep the artist's work running, it becomes more of a challenge to assign value to the work in the future. Other forms of digital media arts work - like Net Art housed on servers - present their own unique challenges to preservation, valuation, and exhibition. Permanent collections may lose Net Art that is not regularly archived and backed-up to servers. Likewise, digital media arts work relying on rapidly evolving technologies like web browsers, operating systems, and hardware are very dependent upon collections' provision of technical support, software upgrades, and technical maintenance. In the future, without the economic and technical support necessary to maintain digital media arts work, society is at risk of losing accessibility to these works.

The challenge of archiving and preserving digital media arts work is an important challenge to consider for digital media artists, curators, and collectors. Traditional forms of artwork are preserved with relatively static technology including lighting, humidity, and climate controls. Museums and collectors use this relatively static technology to control the physical environment in order to preserve sculpture, paintings, and photography. Having the ability to preserve these types of artwork helps curators and collectors maintain the value of their collections. Curators and collectors are more familiar with these traditional and more static preservation technologies than the latest digital media arts technologies that rapidly evolve, become obsolete, and require constant maintenance. Without the required maintenance for digital media arts work, this type of work faces the challenge of losing its existence. This potential loss of digital media arts work challenges the valuation of digital media arts work.

\subsection{Technology and accessibility}

The technology of and accessibility to digital media arts work in public and private spaces present challenges to valuing digital media arts work. Without proper technology and support for exhibiting digital media arts work, visitors are unable to access, experience, and value digital media arts work. The limited accessibility to digital media arts work when compared to traditional fine artwork creates the perception among visitors that traditional artwork is more highly valued in cultural institutions and spaces than digital media arts work.

Providing technical support is also a challenge to collections exhibiting digital media arts work; if these works are not exhibited, it is difficult to value them. Both public and private collections face challenges providing spaces with the technology necessary for exhibiting digital media arts work. Many traditional exhibition spaces are not set up to support the technical needs of digital media arts work. Examples of this include exhibition spaces that do not have enough digital audio-visual, Internet, and power connections. These exhibition spaces are ill equipped to make the technology necessary for exhibiting digital media arts work invisible to the visitor. Visitors are easily distracted by the technology used to exhibit digital media arts work and when the technology used in a work is too visible, visitors tend to focus on how the technology works instead of valuing the work itself.

Accessibility and integration are challenges to exhibiting digital media arts work in collections. These challenges are revealed by the lack of representation of digital media arts work in cultural institutions like art museums. This lack of representation of digital media arts work in exhibition spaces restricts visitors from experiencing and valuing digital media arts work. In contrast to digital media arts work, traditional fine artwork is prominently displayed in exhibition spaces. The prominent display of traditional fine artwork in collections creates a perception in visitors that traditional fine artworks are of greater socio-cultural-economic importance than digital media arts work.

When cultural institutions display digital media arts work, it is often on a smaller scale than traditional fine arts exhibits. The digital media arts work are often restricted from the main exhibition spaces for display in what Paul (2008) describes as digital media art 'lounges' that are segregated from primary galleries, sometimes below ground level. The exclusion of digital media arts work, especially the restriction, containment, and display of this work in the least desirable physical spaces of cultural institutions, presents visitors with challenges to valuing this body of work. For example, visitors who enter the lobby of a large art museum might find a significant amount of exhibition space dedicated to traditional fine art. Visitors searching for digital media arts work might find these works after descending into the bowels of a museum.

When visitors and collectors are unable to enjoy and experience digital media arts work because of a lack of accessibility and technical support from public and private exhibition spaces, these spaces 
create challenges for the valuation of digital media arts work. Cultural institutions failing to provide technical support for the exhibition of digital media arts work restrict the public from enjoying and valuing digital media arts work. This type of analogue versus digital artwork imbalance with visitors being more exposed to traditional fine artwork than digital media arts work leads visitors to value traditional fine artwork more than digital media arts work.

\section{DISCUSSION}

\subsection{Providing value to the dematerialised}

There are challenges to the valuation of digital media arts work because traditional valuation models are not easily applied to digital media arts work. Possible solutions to the challenges in the valuation of digital media arts work combine economic, preservation, technology, and accessibility strategies. Some possible economic solutions to the challenges of valuing digital media arts work include assessing fees, forging partnerships, creating hybrid and limited-edition works, and using formal agreements.

There is nothing new about public and private exhibition spaces charging admission fees to generate revenue to support art collections. However, charging admission fees offers a possible solution to the funding challenges for digital media arts work exhibitions. When public and private exhibition spaces charge admission fees to support digital media arts work exhibitions, the arrangement relieves the pressure of selling digital media artworks to generate revenue. An example of the public's willingness to pay admission fees to experience digital media arts work occurred during the Whitney Museum of American Art BitStreams exhibition. In 2001, BitStreams was so successful that visitors waited in long lines to enter the digital media arts exhibition. Private collections and galleries could also charge nominal fees to visitors to experience digital media arts work. This type of economic support for experiencing digital media arts work in galleries and private collections would help support digital exhibitions without relying solely on the sale of physical artwork to provide revenue. As more visitors are exposed to digital media arts work, these visitors have a greater opportunity to appreciate and value exhibited digital media arts work.

Admissions fees, corporate partnerships, and hybrid works offer possible economic solutions to the dearth of funding for galleries that support digital media arts work. Online galleries providing curated digital media arts work could charge nominal fees for visits to their web sites. These websites could also generate revenue through corporate sponsorship and advertising. A range of media industries including newspapers, music, film, television, and photography are testing these models online. Brick and mortar galleries are experimenting with representing digital media arts work that combine the physical with the virtual. These limited edition pieces combine computer, screen, and software with sculptural forms into the finished work. Gering \& López Gallery sells this type of hybrid digital media arts work by artists like John F. Simon, Jr. at prices ranging from $\$ 20,000$ to $\$ 50,000$ (Delson, 2001). Galleries can also familiarise collectors with newer forms of artistic expression in the digital media arts by exhibiting physical work that combines digital work like Net Art with sculpture. As collectors become aware of this hybrid digital media arts work, they have a greater opportunity to appreciate and value digital media arts work.

A possible solution to overcoming the challenges of valuing reproducible digital media arts work is for collections to sell artists' signed and numbered 'limited-edition' CDs, DVDs, exhibition samples, or documentation of the show on portable media (Delson, 2001). If they are seen as having value to the collector, these mass-reproducible exact digital copies could generate additional streams of revenue. The artist's signature on the media could provide this additional value to the collector. Selling digital media provides money to private and public institutions to cover exhibition expenses and can provide support to digital media artists. For example, the Whitney Museum of American Art (2001) sold CDs of the digital sound works from the Bitstreams exhibition. Visitors who purchased these CD's may have had a diminished experience of the sound works at their homes because of differences between the professional grade equipment at the museum and the consumer grade equipment at visitors' homes. However, the audio CDs offered visitors a fragment of the exhibition that could be valued. This model of selling copies of artwork on portable media also provides an alternative to the 'less is more' traditional economic valuation model. Increased sales of the digital copies of the work provide greater economic support to digital media artists and more accessibility to their work.

A possible solution to the challenge of valuing digital media arts work that can be easily copied from one computer to another is to use licensing agreements. In a similar way to how software is licensed from developers, the digital media arts work, 'Earth' was leased from the artist John Klima for $\$ 1,000$ a year for display in the National Library of Medicine building (Delson, 2001). Using this valuation model, licences could be granted to public and private exhibition spaces for limited periods of time. Limited licensing adds economic 
value to digital media arts work by providing a limit to the works availability for display. Collections could compete in the marketplace for exclusive licences for digital media arts work. With the licences, digital works could be exhibited for a limited time and generate revenue with admission fees. Private collections paying for lifetime exclusive licences granted by artists would provide provenance and economic value to digital media arts work.

Assessing fees, forging partnerships, creating hybrid and limited edition works, and using licensing agreements provide economic valuation models for accessing and collecting digital media arts work. These economic valuation models provide ways for collectors to more easily appreciate digital media arts work. Collectors who lack physical space for their collections may be interested in acquiring digital media artwork because it often requires less physical space than traditional artwork or it can be experienced online in virtual spaces. Also, because reproduction costs are often lower for digital media arts work than physical artwork, younger collectors with less capital to invest on older and more expensive traditional artwork might be interested in collecting digital media arts work. By minimising the cost and space limitations to collecting artwork, digital media arts work becomes more accessible to younger audiences. Getting younger audiences involved in appreciating this type of work will be critical for the future valuation of digital media arts work.

\subsection{Preservation}

Materiality and durability affect valuation of artwork in the traditional fine arts. Materiality and permanence add value to artwork because they provide a greater potential for people to experience the work in the future. Traditional fine artwork differs from digital media arts work because of digital media arts work's use of quick changing technologies. Digital media art works are often referred to as 'ephemeral and unstable' (Paul, 2008). It is a form of artwork that is assumed to be difficult to archive because of its dematerialised form and its changing use of technology. Digital media arts work requires a range of preservation solutions to maintain its value in the future.

A liability to the valuation of digital media arts work is collectors' fears of the obsolescence of the digital technology used in a work. Collectors worry about the potential that the technology necessary to experience digital media arts work will not be available in the future. Finding solutions to archiving digital media arts work requires getting cultural institutions, artists, and scholars involved in the archiving process. Connecting cultural institutions with artists and scholars helps curators standardise methods for preserving digital media arts work. For example, The Variable Media Network began as collaboration between the Guggenheim Museum, the Daniel Langlois Foundation for Art, Science and Technology, the Berkeley Art Museum, and academic scholars to develop best practices for preserving contemporary forms of artwork (Wands, 2006). In a similar collaborative effort, Rhizome's founder and Brown University scholar, Mark Tribe, and the futurist, Bruce Sterling, worked with The Variable Media Network to identify and write about solutions to challenges in preservation (Sterling). These collaborative efforts between cultural institutions, curators, and scholars resulted in the identification of methods for preserving and archiving digital media arts work.

Digital media arts work need to be preserved so that future generations have the opportunity to experience, enjoy, and value them. If contemporary solutions for preserving digital media arts work are not employed, society runs the risk of losing a broad range of important new forms of artwork. Paul (2008) writes 'Bits and bytes are in fact more stable than paint, film, or videotape'. If cultural institutions and collections are successful preserving digital media arts work, Paul's statement about the stability of digital works may prove correct. Collections that successfully preserve digital media arts work provide accessibility to digital media arts work to larger audiences and future generations to experience, appreciate, and value these works.

\subsection{Technology and accessibility}

Digital media arts work face challenges with accessibility and integration to private and public collections. A solution to the challenge of displaying digital media arts work in collections is to augment older spaces with smart technology that provides wired or wireless connections supporting digital media arts work. Smart technology includes sound and video connections to audio speakers, digital projectors, the Internet, and power connections. Using smart technology in existing exhibition spaces provides digital media arts work greater visibility and the opportunity to be more highly valued by the public.

Technology should not be the main consideration in the valuation of digital media arts work. Rather, the content of digital media arts work should be the primary focus in its valuation. There are solutions to help visitors focus on the content of the media arts work and minimise their attention on the technology running the digital media arts work. Collections can hide and embed technology inside or behind walls and pedestals in exhibition spaces. Wireless technologies provide cable-free access to the 
Internet, servers, networks, and more recently, even electrical power to run digital media arts work. Collections can also minimise visitors' attention on the technology running digital media arts work by positioning speakers in the ceiling and orienting them in a way that keeps them hidden and directs sound to specific locations in the exhibition space. Similarly, through the use of flexible ceilingmounted hardware, collections can position projectors in unobtrusive and out-of-sight locations.

It is impossible to foresee all of the technical needs of digital media arts work. However, a broader range of digital media and power connections are necessary for exhibition spaces to successfully support digital media arts work. Providing greater accessibility, using technology, and supporting digital media arts work in public and private spaces will help overcome challenges to valuing and exhibiting digital media arts work.

\section{CONCLUSION}

The valuation of digital media arts work is being reshaped by the challenges of the economics of dematerialisation, preservation, technology, and accessibility. These challenges present the need for a paradigm shift in the valuation and exhibition of digital media arts work in public and private spaces. The possible solutions to these challenges that are presented in this paper provide opportunities and spaces for the occurrence of this paradigm shift in assigning value to digital media arts work. By demanding that museums and collections cater to their tastes for digital media arts work, future generations of digital media art enthusiasts and supporters may be instrumental to the changing valuation of digital media arts work. Future generations that grow up with digital media arts technologies may play a large role in bridging the digital divide and shifting the paradigm in the valuation and exhibition of digital media arts work.

\section{REFERENCES}

Barber, J. (2008) Digital archiving and "The New Screen." In Adams, R., Gibson, S. and Arisona, S. (eds.), Transdisciplinary digital art: sound, vision and the new screen. Springer, New York.

Benjamin, W. (1968) The work of art in the age of mechanical reproduction. In Arendt, H. (ed.)

Illuminations: Essays and reflections. Schocken, New York.

Whitney Museum of American Art (2001). Bitstreams: Sound works from the exhibition at the Whitney Museum of American Art, CD, JDK, New York.

Delson, S. (2001) If Picasso were a programmer. Forbes, pp. 44-47. 25 June.

Innis, H. (1972) Empire and communications. Oxford University, Oxford.

Paul, C. (2008) Digital art. Thames \& Hudson, New York.

Sterling, B. Introductions: Digital Decay. Variable Media Network. http://variablemedia.net/pdf/Sterling.pdf (23 March 2010).

Sturken, M and Cartwright, L. (2001) Practices of looking: An introduction to visual culture. Oxford University, Oxford.

Wands, B. (2006) Art of the digital age. Thames \& Hudson, New York. 